\title{
The Evaluation Analysis of Social Governance Efficacy in Social Organiza- tions Based on Fractional Theory
}

\author{
Feihu Li*
}

Chongqing City Management College, Chongqing 401331, China

\begin{abstract}
This paper explores the evaluation analysis of social governance efficacy in social organizations based on fractional theory. To respond to these emerging social development issues, the CPC Central Committee decided to strengthen social management and social construction, and made some guide social management innovation principles and methods, the local government is based on the actual situation around, develop appropriate policy, launched a nationwide social management innovation practice, and achieved some success and experience. Therefore, must take certain measure to promote the countryside new social organization's development.
\end{abstract}

Keywords: Fractional theory, social governance efficacy, social organizations, the evaluation analysis.

\section{INTRODUCTION}

Since reform and opening, China has entered a period of history of the fastest growing economies in just thirty years' time, China's reform and opening-up policy unleashed amazing strength, to 2012, and China's economy has been ranked second in the world. Rapid economic development, China 's social management and social construction is still relatively backward, the emergence of such rich-poor divide, high unemployment, a huge number of sudden mass incidents and other factors that threaten social security and stability. To respond to these emerging social development issues, the CPC Central Committee decided to strengthen social management and social construction, and made some guide social management innovation principles and methods, the local government is based on the actual situation around, develop appropriate policy, launched a nationwide social management innovation practice, and achieved some success and experience. This article is a combination of social management innovation in a number of specific practices to the social management innovation model systematic research, with a view to the future of social management innovation to provide reference, ideas and direction $[1,2]$.

The enhancement and innovation in social management is the key element in building a harmonious society, and how to build a well-organized society is an urgent issue in modern China. Community is the basic social unit and major living space [3]. Therefore, a harmonious community is the important foundation of a harmonious society and the criteria to judge the outcome. Nowadays, with the development of economic and social transformation, and the process of urbanization, the urban population increased greatly. Also, a lot of social contradiction and interest conflicts have been accumulated [4].
The various social needs should be satisfied in community, and the localization of social problems in communities has become an irreversible trend. Under such circumstances, traditional community managerial pattern showed it shortcoming day by day, such as, outdate managerial measures, extensive patterns, high cost and low quality of service, which can hardly fulfil the increasing needs upon public services in urban communities. So, with the thorough reflections on traditional community managerial patterns, Chinese local government starts all types of exploration in transformation of urban community managerial methods $[5,6]$. Urban community grid management, as an excellent and important measure in social management innovation, gained great concern from the government, academic researchers and common people, since the first day. With the active promotion of the government in recent years, the exploration and completion of urban community grid management is on an expressway in many experimental sections of Chinese cities.

\section{THE CURRENT SITUATION OF SOCIAL GOV- ERNANCE IN CHINA}

According to the Third Plenary Session of 18th CPC Central Committee about the reform objective of "perfecting and developing the socialist system with Chinese characteristics", and the proposition of social governance innovation and its problems encountered in practice, it is urgent to strengthen the institutional innovation of social governance [7]. Specifically, taking the institutional innovation problem of social governance as the research subject, it is based mainly on three aspects of thinking:

First, strengthening the social governance is an inevitable result of the governmental function evolution in human social development. Since the dawn of human society, the social governance function existed. In modern society, driven by the factors of the change of social structure, the expansion of public affairs, the civil consciousness enhancement, social governance function is more and more highlighted. Espe- 
cially when appearing some social problems such as the social order disorder, the social contradictions surging, the social conflict expansion, the social justice collapse, the society risk explosion, strengthening the social governance to maintain the stability of social order and improving the legitimacy of the regime, becomes a focus of the governmental function reform.

Second, the social governance innovation is the inevitable requirement of China's economic and social coordinating development strategy. The phenomenon of "a long leg with economy and a short leg with society", not only seriously restricts the further development of socialist market economy, but also causes a hidden trouble to the social harmony and stability due to many social contradictions and problems long-term accumulation that can't be settled timely. Therefore, it is necessary to strengthen and emphasize social governance innovation further. Third, the institutional innovation is the core appeal to deal with many problems in the process of social governance innovation. Currently, local governments appear many wrong practices around social governance innovation, which mainly lies in the lag or deficiency of institutional change, namely no going to seek the institutional breakthrough, and ignoring the core value of institutional change in the process of social governance innovation.

Practical experience and general idea of the institutional innovation of social governance shows:

First, it is the foundation of the institutional innovation research of social governance to define basic connotation, function value, theoretical logic and analytical paradigm of the institutional innovation of social governance. The institutional innovation of social governance not only includes the general concept characteristics of institutional innovation, but also contains rich theoretical connotation. Institutional innovation is the essence and core of social governance innovation, which helps to promote the rule of law, standardization, scientization of social governance, and guarantee the continuous innovation of social governance, evade the risk of social governance institution. The institutional innovation of social governance is a new academic issue, and its direct theoretical source is rare, so it is necessary to construct the theoretical logic of institutional innovation of social governance for laying ideological foundation of this paper research. Suitable for the essential connotation of institutional innovation of social governance and China's unique environment of social governance institution, constructing the analytical paradigm of institutional innovation of social governance is particularly important. Based on abroad, combining the actual conditions contemporary Chinese social governance, of the existing research path at home and institutional arrangement problem of constructs an eligible framework, namely analytical paradigm of "concept-structure-behaviour", to make more persuasive explanation aimed at institutional innovation problem of contemporary China's social governance.

Second, constructing the theoretical framework of institution innovation is not only a basic theoretical discussion and a foundation meaning for further research on the institutional innovation of social governance, but also a research content of realistic significance highly and an important guiding value for the practical work deployment or future direction of the institutional innovation of social governance. This paper takes the institutional paradigm of "concept-structurebehaviour" as the analysis mainline, reconstructing the theoretical framework of China's institutional innovation of social governance from five aspects such as goal, subject, driving force, resistance and manner. The goal system includes: the value dimension with social governance mode of "small government and big society"; the structural dimension with scientific, standardized, efficient and convenient social governance system [8]; Behaviour dimension with multivariate, collaborative and cooperative social governance mechanism. The subject mode is the "government-leading multilateral participation", which is promoted and gradually formed by the "introduction" of governance and good governance concept, the institutional structure optimization and the development of public participation behaviour. The driving force includes: the intrinsic motivation of modern concept embedded, the external motivation of institution supply-demand disequilibrium and the direct motivation of rational choice under the view of interest driving. The resistance includes: the ideological resistance of concept change lag, the structure resistance of institutional declining and its path dependence, and the behaviour resistance of vested interests boycott. The manner selection shows some characteristics and trends such as radical idea transforming into progressive idea, almighty model transforming into governance model, control behaviour transforming into service behaviour.

Third, it need be experientially proved that the explanatory power is high or low, and the construction force is strong or weak of the analysis paradigm of institutional innovation of social governance for its theoretical framework. Furthermore, the institutional paradigm of "conceptstructure-behaviour" being suitable for China's current institutional innovation problem of social governance is only verified by experience. Therefore, it is very necessary to carry out the experiential analysis for specific institutional innovation of social governance. This paper selects the internment and repatriation institution as an experiential analysis specimen of institutional innovation of social governance, mainly analysing its reform logic from five aspects such as goal, subject, motivation, obstacle and manner, and outlining the beneficial enlightenment toward the institutional innovation of social governance. The goal mainly manifests: from the view of national power to the view of civil rights, from the self-interest system to the service-oriented system, from the simplified control to the diversity aid. The subject shows a trend of diversification, which is promoted and gradually formed by the growth of awareness of rights and interests of vulnerable groups, the harmonization of social security system, scientific and democratic decision-making of salvation. The motivation includes: the ruling idea renewed and the social concept advanced, the law conflict and the institution alienation, the "reversed" effect of public participation. The obstacle includes: the order view of taking nation as the centre, the restriction of institutional path dependence and the behaviour anomie of law enforcer. The manner is showing some characteristics such as "closed" concept transforming into "open" concept, "monopoly" system transforming into "participatory" system, "forced" behaviour transforming into "voluntary" behaviour. The enlightenment mainly includes: 
concept change is the fundamental premise of institutional reform and innovation, institutional structure optimization is the core path of institutional reform and innovation, behaviour improvement is the key demand of institutional reform and innovation $[9,10]$.

Fourth, discussing the path selection of institutional innovation of social governance is the ultimate goal of this paper. The construction and experiential verification of institutional paradigm of "concept-structure-behaviour" have laid the foundation for exploring further the forward path to strengthen institutional innovation of social governance. The thesis thinks the path selection of institutional innovation of social governance should be mainly commenced from three aspects such as strengthening the concept change, optimizing the institution structure, improving the subject behaviour. Specifically, first, strengthening the concept change of institutional innovation of social governance should base on two aspects of the basic value orientation and ideological innovation. Second, optimizing the system arrangement of institutional innovation of social governance should base on five aspects, such as reconstructing the relationship between government and society, perfecting the social governance function system, recombining the social governance organization structure, improving the relevant social governance regulations, and strengthening the construction of institution implementation mechanism. Third, improving behaviour of institutional innovation of social governance should base on subject aspects, such as strengthening the leadership of party committee of CPC, highlighting the National People's Congress supervision, accelerating the governmental responsibility, pay attention to judicial protection, promoting the social coordination, and enhancing the public participation. However, whether this theoretical paradigm can contain and explain all the present China's institutional innovation problems and difficulties of social governance, still need be discussed further. Though this paper has verified the relevance of analysis path of "concept-structure-behaviour" by experiential analysis of the internment and repatriation institution reform, But, the internment and repatriation institution being or not being sample and universal relative to the institutional innovation of social governance, has yet to be proved further. Limited to paper length and personal ability, those problems all of above being solved need more scholars to research collectively.

\section{THE FRAMEWORK OF FRACTIONAL THEORY}

Given a set of articles by a researcher ranked in decreasing order of the number of citations that they received, the $f$ is the largest one among all the geometric averages of each publication and the corresponding citation. Mathematically, $\mathrm{f}$ -index can be expressed by

$$
f=\max _{1 \leq j \leq m} \sqrt{j n_{j}}
$$

For the indicator which became better and bigger:

$$
\begin{aligned}
& z(i, j)=S_{\min }+ \\
& \frac{e(i, j)-\min _{j} \mathrm{e}(i, j)}{\max _{j} \mathrm{e}(i, j)-\min _{j} \mathrm{e}(i, j)} \times\left(S_{\max }-S_{\min }\right)
\end{aligned}
$$

For the indicator which became better and smaller:

$$
\begin{aligned}
& z(i, j)=S_{\max }- \\
& \frac{e(i, j)-\min _{j} \mathrm{e}(i, j)}{\max _{j} \mathrm{e}(i, j)-\min _{j} \mathrm{e}(i, j)} \times\left(S_{\max }-S_{\min }\right)
\end{aligned}
$$

For e-plus in some appropriate value indicators:

$$
z(i, j)=S_{\max }-\frac{\left|e(i, j)-e_{0}\right|}{\left|e(i, j)-e_{0}\right|+\mathrm{e}_{0}} \times\left(S_{\max }-S_{\min }\right)
$$

The countryside new social organization can close contact and communication between the government and farmers, improve the farmers' interest expression channels and mechanism, convey the government decision-making and assist implementation, play a "bridge function". "When some group or individual present a political requirement, the political process starts. Contemporary china political process begins as people belonging to different social interest groups and organizations representing people express a certain political requirements. Modern society is the organization of the society essentially, people in the face of a strong government is fragile weak, so must participate in some organizations, through the organization to express their interest demands is the most effective." It is the core task of the rural modernization in China that the majority of villagers' lack of self-expression and self-organization will be led to selfexpression and self-organization of modern citizen road.

In the traditional Chinese rural society, besides the Communist Party of China, China does not have nearly specialized organization on behalf of the interests of farmers, which result in two consequences to a certain extent: on the one hand, government doesn't fully understand for information on rural areas, thus can not really understand the needs of farmers, the policies will be difficult to implement; On the other hand, due to the lack of a variety of channels and mechanisms of expression interests require, the farmer own requests and the ideas are unable to reflect smoothly. So in the government's rural policy-making process, due to lack of necessary communication, both sides point of view is difficult to reach agreement. The countryside new social organization's existence is not only helpful to the agricultural policy-making scientific and rationalization, but also helpful to provide the dynamic real-time information feedback in the process of agricultural policy implementation to correct the deviation of agricultural policy implementation or test the performance of agricultural policy. Therefore, the countryside new social organization becomes important resources that the government and legislative bodies understand the relevant agricultural policy implementation.

In the evaluation of the ICP, it can be estimated the edge nodes for selecting is that:

$$
\begin{gathered}
(c m(k, j))_{n_{c} \times m_{a}}=\sum_{i \in p c(k, j)} w_{i} / \sum_{i=1}^{n_{c}} w_{i} \\
p c(k, j)=\left\{c_{i} \mid\left(a_{k} \succ a_{j}\right) \cup\left(a_{k} \sim a_{j}\right)\right\}
\end{gathered}
$$


The countryside new social organization can renew the government's social management idea, promote the shift of governmental functions, and assist the government in implement of decisions, play "the assistant functions." At present the governance of rural grassroots government still rely mainly on the administrative system to implement the national policy, inefficient, ineffective has been highlighted.

The absorption of the countryside new social organization in governance will help to solve three agricultural problems. In the reform government will increasingly withdraw from the civil society, the unloaded functions and services will undertake by other organizations which are the countryside new social organizations. The countryside new social organization can do the matter can be summarized into two categories, one is that the government should do, but without enough time does the matter, or did not have the energy to do; two is the government although thinks to do, but as long as the countryside new social organization has done first, it will not oppose matter. In essence although the countryside new social organization belongs to the non-official organization, but shares the government's part practical work as the government policy's acting organization, which will help promote the success of the reform of government institutions. The government in the past faced scattered individual farmers, either mobilization or supervision are ineffective, and now the countryside new social organization concrete implements decision-making, which makes the government effort devoted to decision making and research on major issues, thus can create a good social organization background for the government function reform.

The countryside new social organization can resolve the conflict between the government and farmers, and maintains the rural community political stability, plays "the buffer function". Currently, China is undergoing social transition, due to rapid economic development, some social conflicts effecting stable social show an increasing trend. The grassroots party and government organization in the rural society is first line, is in the contradictory first line, become another side of the contradiction. This kind of direct bilateral contact type conflict is difficult to properly resolve by government organizations. At present rural community's contradiction and the conflict are prominent, and have worsened tendency. As the government and the farmers outside a" third party", the countryside new social organization is feasibility as a mediator. We need to further play social integration role of the countryside new social organization function and organize the different interest groups and social groups in rural areas through a variety of ways. The purpose of the countryside new social organization is not to replace the party and the government's role, but to optimize and reorganize social governance and conflict resolution mode in the new economical pattern and social structure. The farmers can express their individual demands and inner dissatisfaction through the legitimate public channel, may prevent, alleviate, and resolve the contradiction affecting rural society stability. Fig. (1) shows the Government, social organizations, the public relations model.

The countryside new social organization can adjust the traditional resources of education, make up for the defects of the formal organizations, train and educate modern farmers,

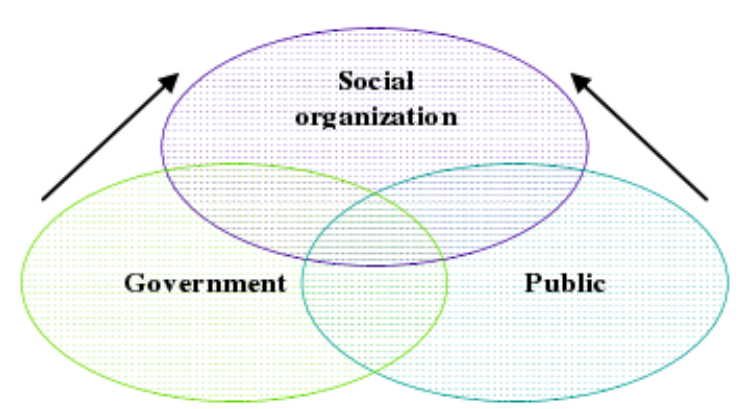

Fig. (1). Government, social organizations, the public relations model.

display "the cultivation function". The Communist Party of China to the farmer's organization, culture and education has a very rich experience, but in the new historical conditions, facing the diversified needs of farmers, the traditional organizational system appeared to be inadequate. At present in countryside Communist Youth League, Women's Federation and even the party branch face the enormous challenges as well as, some places even are at the paralysis condition. In fact, relying solely on the formal organization to educate the farmers already cannot meet the requirements of market economy. From the experience of developed countries, the countryside new social organization is the most effective and convenient carrier to educate and train farmers. In the broad sense, countryside new social organization for farmers' education is far more than the technical aspects, the farmers participating in the daily activities of the organization accept many aspects of education, "the organization can develop farmers' cooperative and mutual assistance, help to change the kind of traditional farmers isolated and closed state; can effectively enhance the awareness of the interests of farmers, educate farmers to unite, and help farmers to take unified action to protect their own interests.

\section{THE SOCIAL GOVERNANCE FUNCTIONS OF THE NEW SOCIAL ORGANIZATIONS}

The countryside new Social organization is after the reform and opening up a new thing, plays an active role in the development of rural market economy. However, due to the constraints of traditional institutional and social environments, the development of the countryside new social organization has lagged behind in economic and social life needs. The development of the countryside new social organization is not perfect, not perfect, and there are a series of problems which do not match current transformation of township government functions, and restrict the countryside new social organization's governance function (Fig. 2).

China's government has promulgated many laws and regulations in agriculture, some of the regulations have a standard and the guidance to the countryside new social organization's management behavior. But so far, our county still does not have a law to the countryside new social organization to make clear, which causes the countryside new social organization in such areas as registration, support and protection lack a legal basis. What the countryside new social organization is based on enterprise legal person or treated according to corporations, has no clear legal definition, that causes part of the countryside new social organiza- 

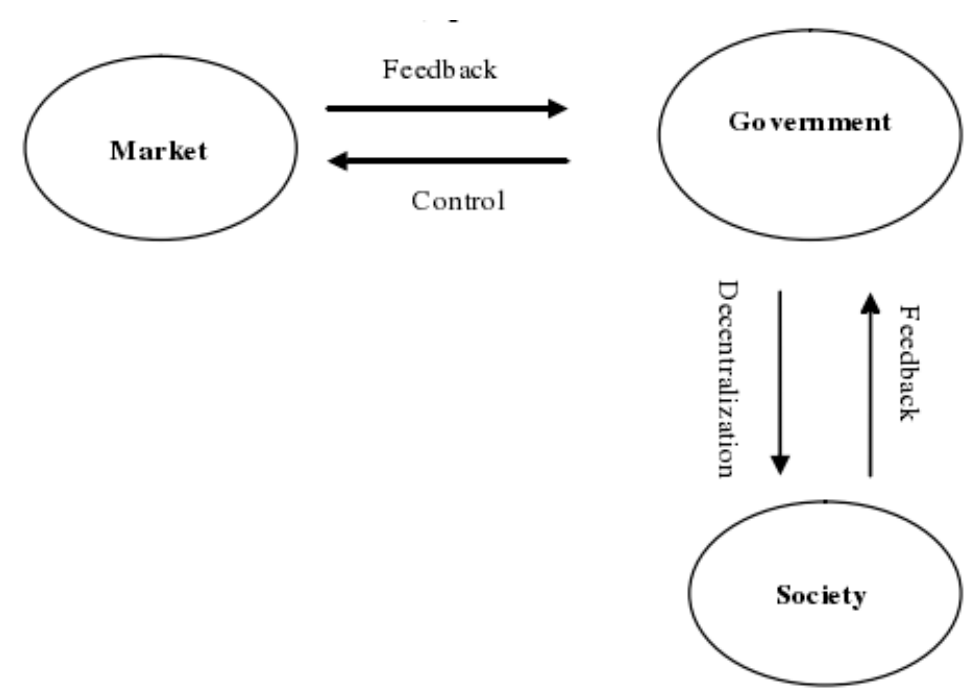

Fig. (2). "Triple treatment" interaction structure.

tion to register as a corporate registrations in the business sector, and part as the juridical associations in the civil sector, and the majority of more the countryside new social organization has not yet approved by the civil registration and the business sector. The countryside new social organizations register in the state of chaos, lead its identity, can not easily be recognized by other legal entities in its foreign relations, presents the dispute also not to be able to obtain the legal protection, does not enjoy from national, the government department's preferential policy, which bring difficulties for their own development and external exchange, to a great extent restrict the development of the countryside new social organizations, and effect its social governance function of play.

Low degree of the countryside new social organization, generally smaller, most in a spontaneous state, and the lack of effective joint with the peasant household, members of the instability, it is difficult to form a close community of interests. Mostly countryside new social organization limits in the range of services in the region, moreover the service content is unitary. Not only that, the countryside new social organization's management mechanism is not perfect, the internal management has great randomness, majority has not organized regulations or the organization regulations is not sufficiently standardized and perfect. Although some have the regulations but execution not strength, some internal systems are not perfect and lack of the effective management system, even some have not the financial management and supervision mechanism. As the countryside new social organization internal management mechanism is not perfect, it may lead to organization leader monopoly resources on major projects and activities in an arbitrary fashion, and ordinary members not to participate in the decision-making opportunities, eventually leading to serious consequences.

The countryside new social organizations due to the establishment of a relatively not formed $\mathrm{d}$ the scale and actual strength, coupled with poor management, resulting short time have in overall low quality. Some organizations lack the necessary fixed assets, there is no economy or reputation for its behaviour to provide guarantee. The countryside new social organization member mostly comes from the farmers, culture quality is low, agricultural technology literacy is not high also. Due to the level of rural education is backward, the countryside new social organizations lack skilled, integrated management talent, quite part of staffs do not undergo a rigorous qualification examination and accreditation, in the practitioner the personnel for part-time duty will be many, the specialists will be scarce. This situation results in lower overall quality of countryside new social organization, adapts the market and society's need with difficulty, does not favour organization own construction.

\section{CONCLUSION}

This paper shows the evaluation analysis of social governance efficacy in social organizations based on fractional theory. Social management in China is now witnessing tremendous changes in its targets and circumstances. The traditional modes and methods social management are no longer able to accommodate the current social situation social trends, and the international trends. This paper puts forward: As economic reform boosts the economic development, China should promote its social transform and construction by the transformation of social management. Social management transformation is the transformation from control to activation of society and enhancement of livelihood.

\section{CONFLICT OF INTEREST}

The author confirms that this article content has no conflict of interest.

\section{ACKNOWLEDGEMENTS}

This work is supported by the Chongqing higher education teaching reform research key project, China (No. 142065), and the Chongqing social sciences planning (Dr, cultivating) project, China (No. 2014BS038).

\section{REFERENCES}

[1] J. Johnson, "Path contingency in postcommunist transformations," Comparative Politics, pp. 253-274, 2001.

[2] K. Thelen, "How institutions evolve," Cambridge University Press, UK, 2004. 
[3] J. Mahoney and D. Rueschemeyer, Comparative historical analysis in the social sciences: Cambridge University Press, UK, 2003.

[4] M. McFaul, "Institutional design, uncertainty, and path dependency during transitions: Cases from Russia," Constitutional Political Economy, vol. 10, pp. 27-52, 1999.

[5] M. D. Aspinwall and G. Schneider, "Same menu, seperate tables: The institutionalist turn in political science and the study of European integration," European Journal of Political Research, vol. 38, pp. 1-36, 2000.

[6] W. R. Clark, "Agents and Structures: Two views of preferences, two views of institutions," International Studies Quarterly, vol. 42, pp. 245-270, 1998.

[7] M. J. Gorges, "New institutionalist explanations for institutional change: A note of caution," Politics, vol. 21, pp. 137-145, 2001.
[8] Greif and D. D. Laitin, "A theory of endogenous institutional change," American Political Science Review, vol. 98, pp. 633-652, 2004.

[9] L. Guanghua, "A structurational analysis of government on-line (GOL) in Canada", Proceedings of 2007 International Conference On Public Administration (3RD), vol. 1, 2007.

[10] L. Guanghua, "E-government, people and social change: A case study in China," The Electronic Journal of Information Systems in Developing Countries, vol. 38, 2009.

[11] L. Guanghua, "E-government, people and social change: a case study in china", The Electronic Journal of Information Systems in Developing Countries, vol. 38, no.3, pp. 1-23, 2009.

Received: June 10, 2015

Revised: July 29, 2015

Accepted: August 15, 2015

(C) Feihu Li; Licensee Bentham Open.

This is an open access article licensed under the terms of the (https://creativecommons.org/licenses/by/4.0/legalcode), which permits unrestricted, noncommercial use, distribution and reproduction in any medium, provided the work is properly cited. 